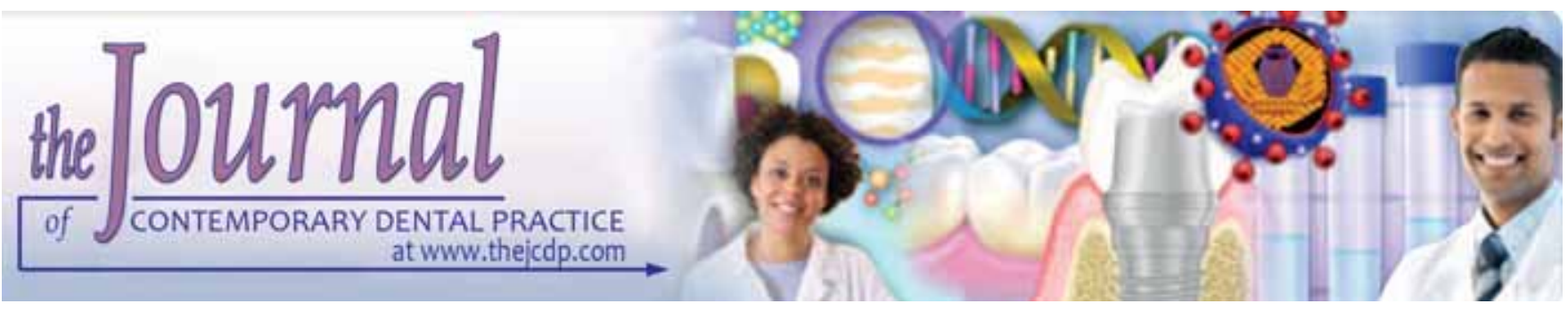

\title{
Effect of Thermal Recycling of Metal Brackets on Shear and Tensile Bond Strength
}

\author{
Y Narendranath Reddy, D Praveen Kumar Varma, Anil G Kumar, KV Sujan Kumar, Surendra V Shetty
}

\begin{abstract}
Aim: The study was undertaken to measure the changes within the mesh pad associated with reconditioning process, measure the bond strength of new and reconditioned orthodontic brackets and correlate the changes in mesh strand diameter with changes in bond strength.
\end{abstract}

Material and methods: 120 clinically normal premolar teeth extracted for orthodontic reasons, were divided equally for bonding with new and recycled brackets using a no-mix type of adhesive. The mesh strand diameters of new and reconditioned brackets were evaluated with a binocular light microscope. Recycling of brackets was done using Esmadent ${ }^{\circledR}$ bracket and band reconditioner.

Results: The mesh strand diameter, tensile and shear bond strength of new and reconditioned brackets were evaluated statistically and the latter was found to show a significant reduction $(p<0.0001)$. However, the bond strength values of the reconditioned brackets were found to be well above the clinically required minimum.

Conclusion: Reduction in mesh strand diameter, as a result of reconditioning process, does not correlate with the change in bond strength between initial and recycled bondings.

Clinical significance: The bond strength of reconditioned brackets is adequate enough to resist the magnitude of forces generated in the mouth, throughout the duration of orthodontic treatment for successful treatment results.

Keywords: Premolar teeth, Brackets, Bonding adhesive, Recycling unit.

How to cite this article: Reddy YN, Varma DPK, Kumar AG, Kumar KVS, Shetty SV. Effect of Thermal Recycling of Metal Brackets on Shear and Tensile Bond Strength. J Contemp Dent Pract 2011;12(4):287-294.

Source of support: Nil

Conflict of interest: None declared

\section{INTRODUCTION}

The evolution of the concept of directly bonding orthodontic brackets to the tooth surface by means of an adhesive material has been a monumental step in the progress of orthodontics. As the manufacturers of brackets are becoming increasingly precise about the quality and design of the brackets, to improve the quality of treatment results, the cost of the brackets also tends to increase. The orthodontists are also faced with a decision of what to do with the used brackets indicating an alternative to the 'disposable' bracket practices. Currently, there is an increased interest in the recycling of metallic direct bonding orthodontic brackets. Several new companies like Esmadent, Orthobond and Orthocycle continue to enter the market with various reconditioning procedures that would be beneficial in minimizing the cost and waste to the orthodontists and ultimately to the patient. It is possible that the various recycling procedure followed may affect the bond strength of brackets by an alternative in their physical, chemical or dimensional configurations. ${ }^{1-7}$

\section{AIMS}

The aims of this study are as follows:

1. To evaluate the effect of commercial thermal recycling procedure on the bond strength of direct bonding orthodontic bracket.

2. To correlate the changes in mesh strand diameter with changes in bond strength.

\section{MATERIALS AND METHODS}

This study was carried out in the Department of Orthodontics, College of Dental Surgery, Mangalore. The material testing procedures were carried out at Hindustan Cables Limited and Regional Forensic Science Laboratory, Hyderabad.

\section{Materials}

1. Premolar Teeth: The sample consisted of 120 freshly extracted human premolar teeth which were extracted for orthodontic purpose. Care was taken to select only intact, noncarious, unrestored teeth which were not hypoplastic and with no development defects. 
2. Brackets: The brackets selected in this study were No. 256-650 series TP Orthodontics Begg Brackets, having a curved base and minimesh type. The new brackets and heat-treated recycled brackets are used in the study (Figs 2A and B).

3. Bonding Adhesive: Bonding material used in this study was Rely-a-Bond (no-mix system) by Reliance Orthodontic Products.

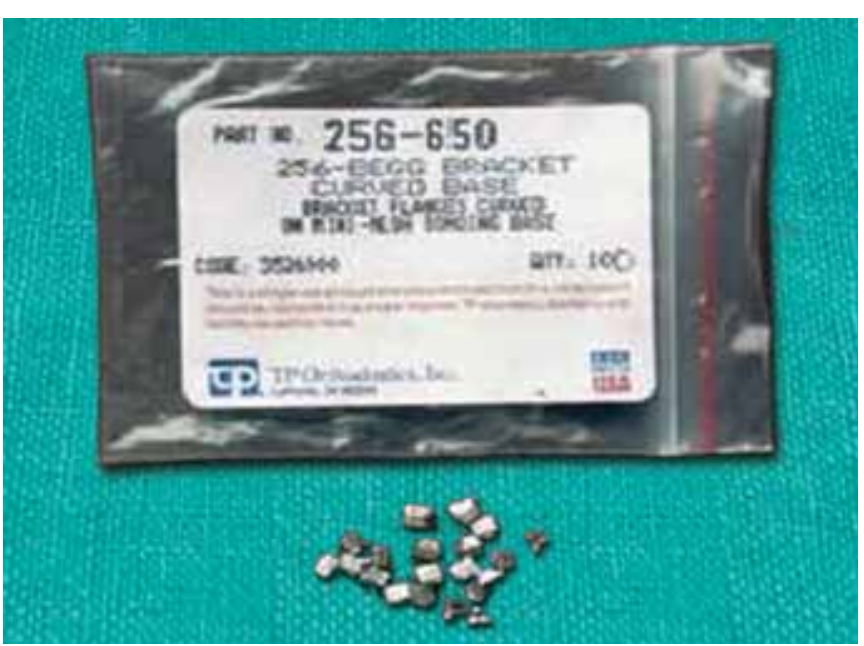

Fig. 1A: New orthodontic brackets used in the study

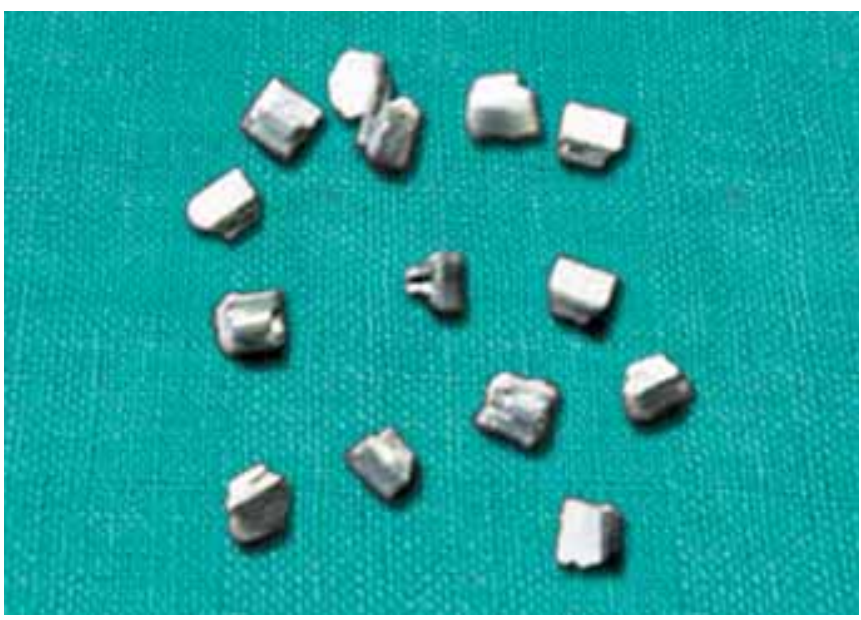

Fig. 1B: Debonded brackets with adhesive

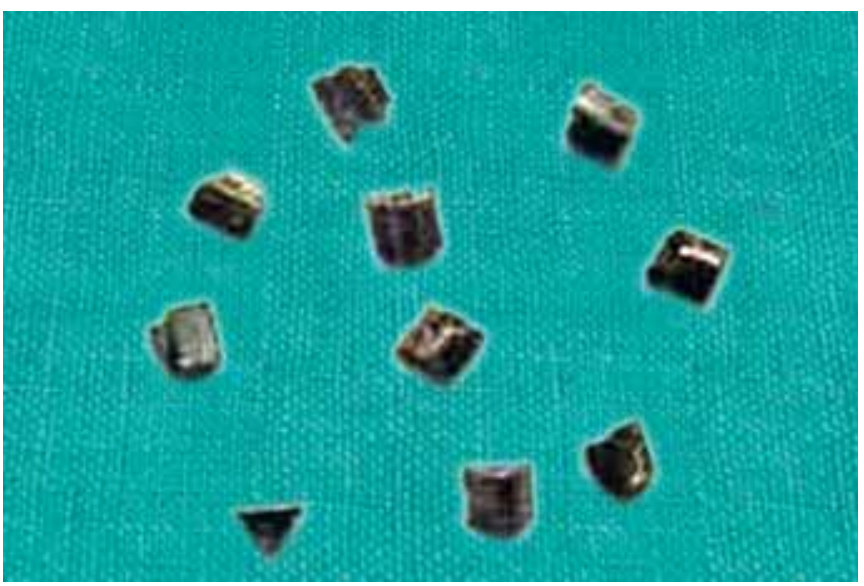

Fig. 2A: Brackets after heat treatment
4. Recycling unit: An Esmadent (Esma Chemicals, Inc) bracket and band reconditioner was used to recondition the brackets (Fig. 3).

\section{Methods}

Each bracket was cleaned of soft tissue debris and a retentive hole was placed on the middle of the root portion with the help of a diamond point bur with an air rotor handpiece perpendicular to the long axis of the tooth for better retention into acrylic. A total of 120 premolar teeth were divided into two groups comprising of 60 in control group and 60 in experimental group. Each group of 60 teeth was further divided into two subgroups of 30 each. For tensile and shear strengths evaluation, the samples were color coded based on chart (Fig. 4). All the teeth were mounted vertically on a cylindrical block of clear methyl methacrylate resin so that the buccal surface of the premolar was perpendicular to the horizontal surface of the acrylic block or parallel to the long axis of the block. The teeth along with the acrylic blocks were stored on $0.9 \mathrm{~N}$ saline until bonding.

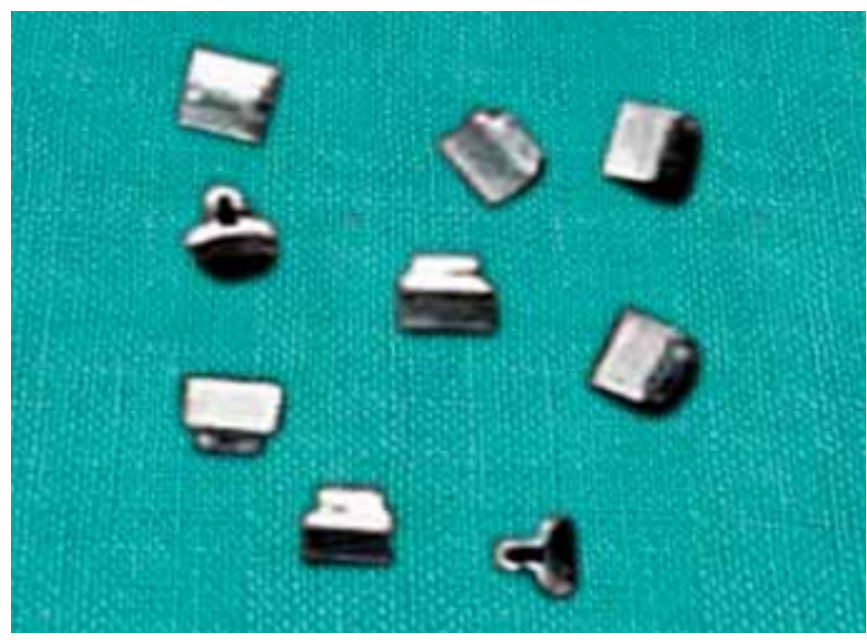

Fig. 2B: Brackets after recycling

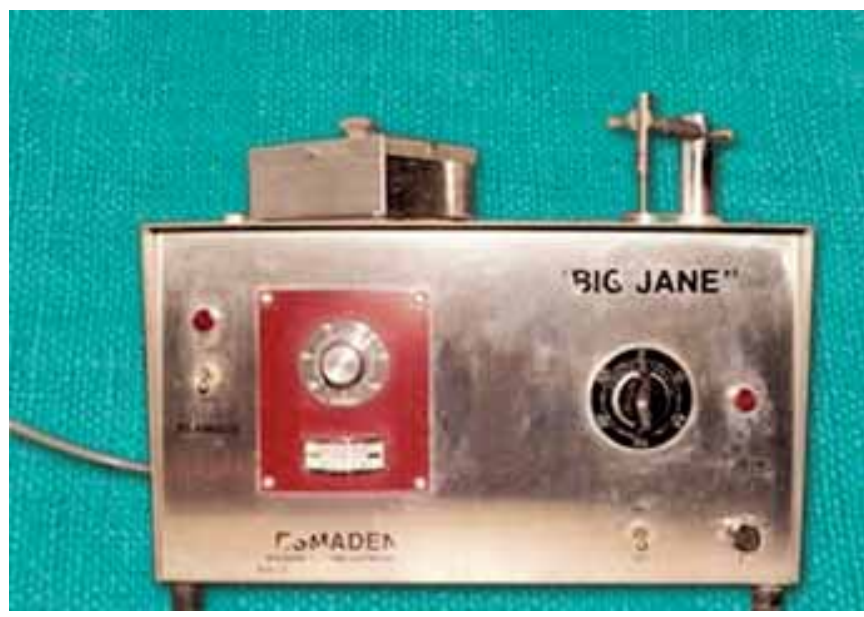

Fig. 3: Recycling unit "Big Jane". Esmadent bracket and band reconditioner 

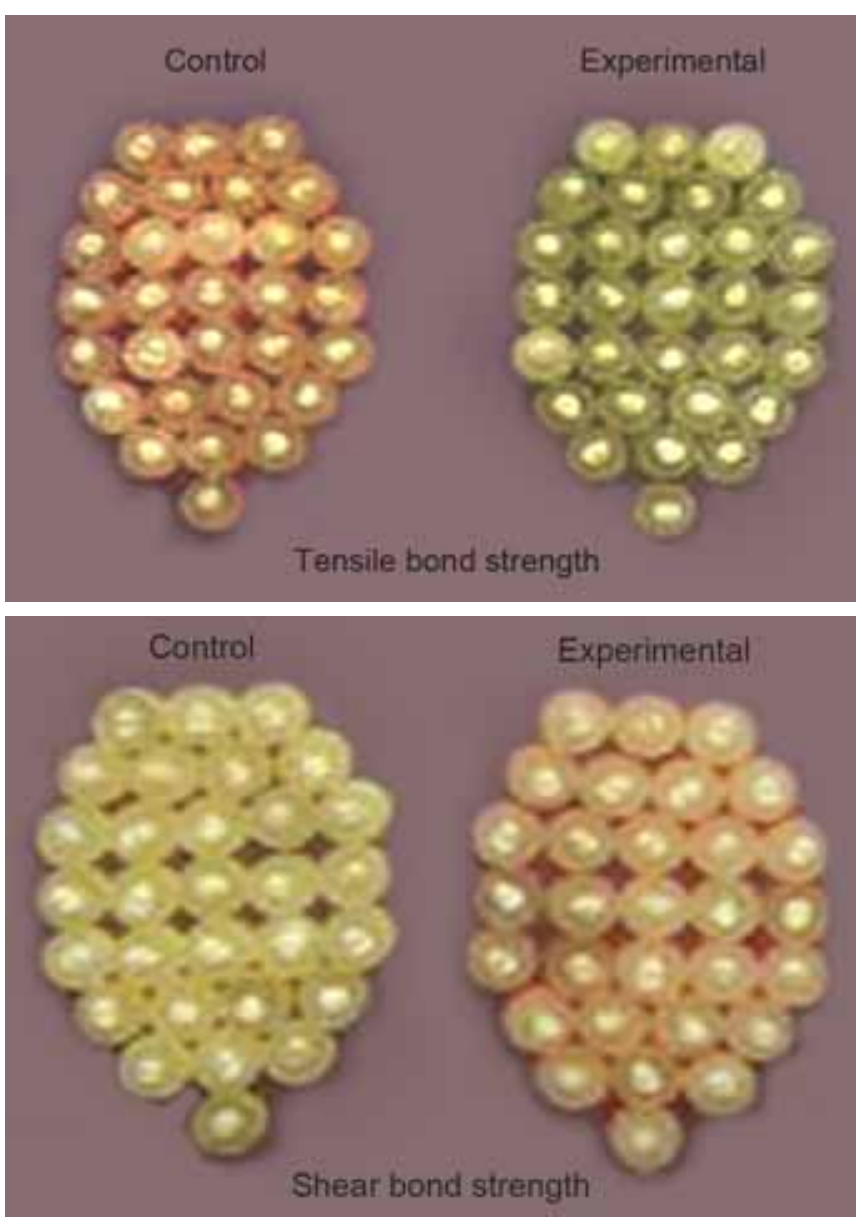

\begin{tabular}{lcc}
\hline & Control group & Experimental group \\
\hline Tensile bond strength & Pink & Green \\
Shear bond strength & Yellow & Orange \\
\hline
\end{tabular}

Fig.4: Control and experimental groups used in the study

\section{Method for measuring the Mesh Strand Diameter}

The mesh pads of the brackets were evaluated with a binocular light microscope to which was added a filer micrometer eyepiece. This eyepiece was calibrated with a 10 micron interval grid micrometer. All the brackets bases were examined keeping in mind the opening of the slot on facial surface facing toward the examiner. A schematic map of the mesh pad was drawn. Five test sites were selected. A test site was defined as a closed aperture bounded by four wire strands not involved with bracket weld. A number was assigned to each of the twenty potential test strands thus designated (Fig. 5). By consulting a table of random numbers, three test strands on each brackets pad were selected for measurement. Strand diameter was measured.

\section{Bonding Procedure}

The bonding procedure was standardized according to Rely-a-Bond specifications by Reliance orthodontic products (Fig. 6).

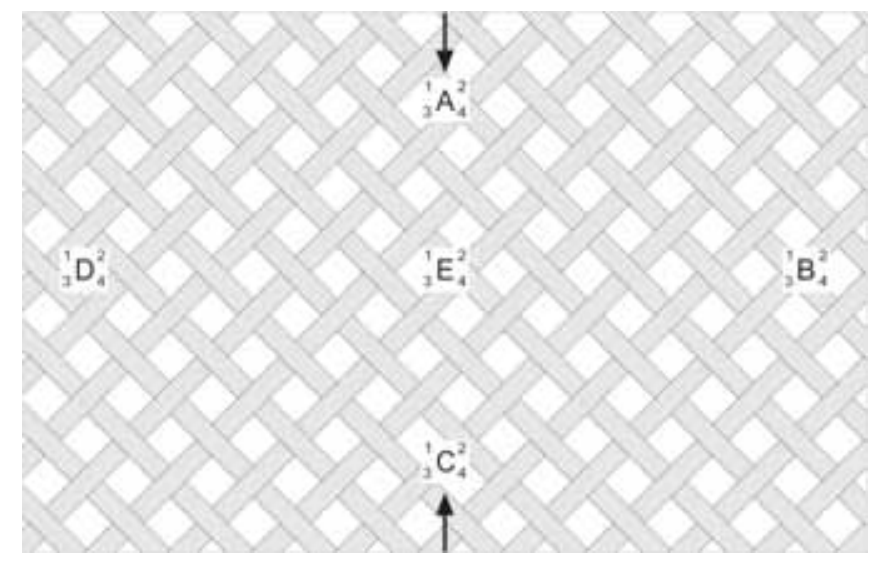

Fig. 5: Schematic map of a mesh pad. Four test sites (A,B,C,D) are located in relation to the periphery of the pad. The fifth test site (E) is located at the center of the bracket. Numbers designate the location of 20 test strands of the wire

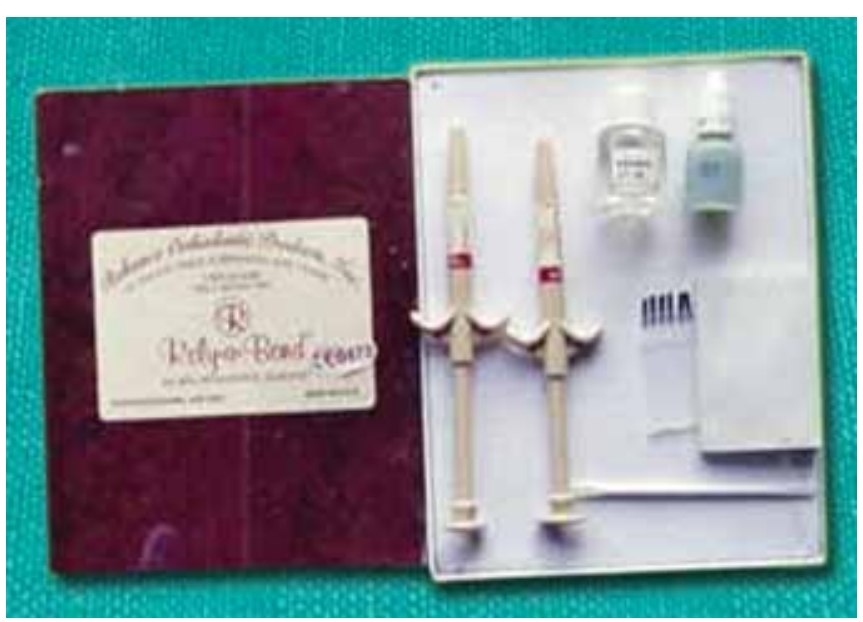

Fig. 6: No-mix adhesive used for bonding

A stainless steel ligature wire of 0.036 " in diameter was passed through the bracket slot, and was twisted to form a single wire, to facilitate strength testing. The specimens were then stored in normal saline of $0.9 \mathrm{~N}$ until bond strength was evaluated.

\section{Method of Mounting and Measuring Strength}

After 48 hours, the specimens were tested using Instron Universal Testing Machine. The specimen was attached to the fixed crosshead (Fig. 7). The free end of the wire was attached to the movable crosshead. A crosshead speed of $5 \mathrm{~mm} /$ minute was selected. Load was applied till the point of fracture that is till the bracket detached from the tooth surface. The electronic reader monitored the peak force that was required to bond the bracket in kilograms. The breaking load was converted into bond strengths using following formula:

Bond strength in $\mathrm{MPa}=$

Breaking load in kilograms $\times 9.8$ $\overline{\text { Surface area of bonding base }\left(\mathrm{mm}^{2}\right)}$ 
The surface area of the bracket base was measured using Tool maker's microscope. It was found to be $9 \mathrm{~mm}^{2}$.

- Thermal recycling procedure: After testing for shear and tensile bond strengths, the detached brackets were subjected to heating process using the furnace of the Esmadent bracket and band reconditioner

- Measuring the mesh strand diameter for recycled brackets: The procedure was repeated for recycled brackets as described for new brackets

- Bonding procedure for recycled brackets: The recycled brackets were bonded to the experimental group of specimens as described for new brackets

- Mounting and strengths testing for recycled brackets: After 48 hours, the specimens were tested using Instron Universal Testing Machine. The bond strengths were evaluated using same procedure used for testing new brackets.

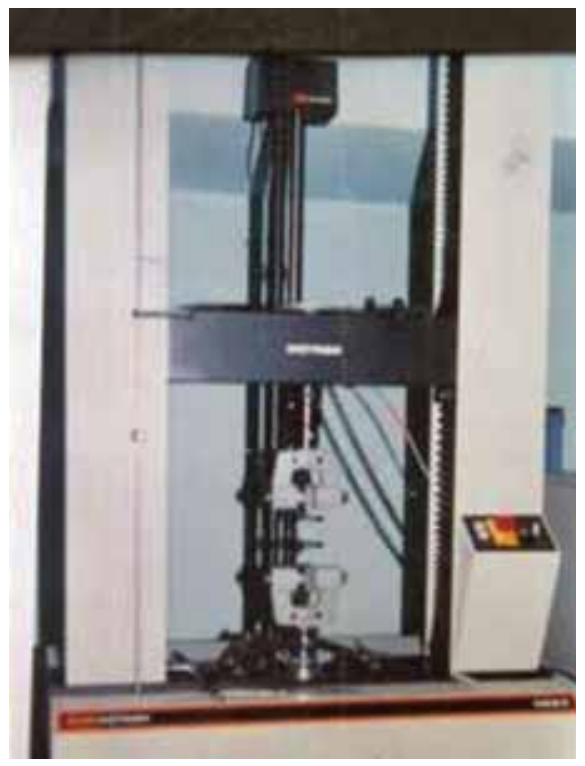

Fig. 7: Acrylic blocks are placed in between the grips of Instron machine for measuring the tensile and shear bond strengths

\section{RESULTS}

\section{Evaluation of Mesh Strand Diameter}

A total of 60 new brackets were evaluated for the mesh strand diameter. Thirty each for tensile and shear bond strength group and the same were evaluated after reconditioning. (Tables 1 and 2, Graphs 1 and 2). The mean and standard deviations for both new and reconditioned brackets were calculated separately for shear and tensile bond strength groups.

The values were subjected to statistical analysis to find whether difference in strand diameter were statistically significant. ' $\mathrm{Z}$ ' test was used to calculate $\mathrm{z}$-value and to find the probability (p-value) (Table 3).

\begin{tabular}{|c|c|c|c|c|c|c|}
\hline \multicolumn{7}{|c|}{ Shear group } \\
\hline & \multicolumn{6}{|c|}{ Mesh strand diameter (in microns) } \\
\hline & \multicolumn{3}{|c|}{ New brackets } & \multicolumn{3}{|c|}{ Reconditioned brackets } \\
\hline 1 & 80 & 80 & 80 & 60 & 70 & 60 \\
\hline 2 & 80 & 90 & 100 & 70 & 70 & 100 \\
\hline 3 & 90 & 100 & 90 & 80 & 100 & 90 \\
\hline 4 & 80 & 90 & 90 & 80 & 60 & 80 \\
\hline 5 & 100 & 90 & 90 & 100 & 90 & 90 \\
\hline 6 & 90 & 80 & 100 & 70 & 60 & 80 \\
\hline 7 & 90 & 80 & 80 & 80 & 60 & 80 \\
\hline 8 & 80 & 90 & 80 & 70 & 80 & 70 \\
\hline 9 & 90 & 100 & 100 & 80 & 60 & 70 \\
\hline 10 & 90 & 90 & 90 & 80 & 80 & 90 \\
\hline 11 & 90 & 90 & 80 & 90 & 80 & 90 \\
\hline 12 & 90 & 90 & 100 & 90 & 80 & 70 \\
\hline 13 & 90 & 80 & 90 & 90 & 50 & 90 \\
\hline 14 & 90 & 100 & 80 & 80 & 70 & 60 \\
\hline 15 & 90 & 90 & 90 & 60 & 70 & 60 \\
\hline 16 & 110 & 100 & 90 & 60 & 70 & 80 \\
\hline 17 & 100 & 80 & 90 & 90 & 80 & 80 \\
\hline 18 & 100 & 80 & 80 & 80 & 80 & 80 \\
\hline 19 & 90 & 80 & 80 & 70 & 80 & 60 \\
\hline 20 & 100 & 90 & 80 & 50 & 80 & 80 \\
\hline 21 & 100 & 90 & 80 & 90 & 70 & 60 \\
\hline 22 & 100 & 100 & 90 & 70 & 70 & 80 \\
\hline 23 & 100 & 90 & 100 & 70 & 80 & 80 \\
\hline 24 & 90 & 90 & 100 & 60 & 60 & 80 \\
\hline 25 & 100 & 90 & 100 & 90 & 90 & 100 \\
\hline 26 & 90 & 90 & 90 & 80 & 80 & 60 \\
\hline 27 & 90 & 90 & 90 & 70 & 70 & 60 \\
\hline 28 & 90 & 90 & 90 & 80 & 70 & 90 \\
\hline 29 & 90 & 90 & 100 & 90 & 80 & 70 \\
\hline 30 & 90 & 90 & 80 & 80 & 70 & 80 \\
\hline
\end{tabular}

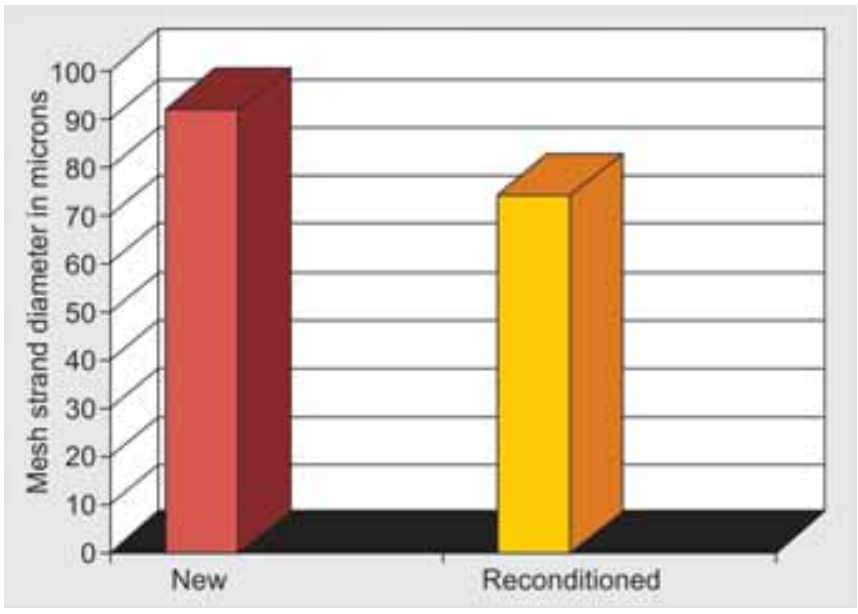

Graph 1: Bar diagram comparing mesh strand diameter of new and reconditioned brackets (shear group)

\section{Evaluation of Bond Strength}

One hundred and twenty specimens were equally divided into 60 control and 60 experimental groups. Thirty specimens from each group were evaluated for tensile and shear strength (Tables 4 and 5).

The mean and standard deviations for both control and experimental groups, for tensile and shear strengths were 
Effect of Thermal Recycling of Metal Brackets on Shear and Tensile Bond Strength

\begin{tabular}{|c|c|c|c|c|c|c|}
\hline \multicolumn{7}{|c|}{ Tensile group } \\
\hline & \multicolumn{6}{|c|}{ Mesh strand diameter (in microns) } \\
\hline & \multicolumn{3}{|c|}{ New brackets } & \multicolumn{3}{|c|}{$\overline{R e c o n d i t i o n e d ~ b r a c k e t s}$} \\
\hline 1 & 90 & 90 & 100 & 90 & 80 & 90 \\
\hline 2 & 90 & 90 & 100 & 90 & 90 & 90 \\
\hline 3 & 90 & 90 & 80 & 90 & 90 & 80 \\
\hline 4 & 100 & 80 & 100 & 90 & 80 & 90 \\
\hline 5 & 90 & 90 & 90 & 90 & 90 & 80 \\
\hline 6 & 100 & 100 & 90 & 100 & 80 & 70 \\
\hline 7 & 80 & 80 & 90 & 80 & 60 & 80 \\
\hline 8 & 100 & 90 & 90 & 60 & 60 & 60 \\
\hline 9 & 100 & 90 & 90 & 70 & 60 & 60 \\
\hline 10 & 90 & 90 & 90 & 70 & 60 & 70 \\
\hline 11 & 100 & 90 & 100 & 80 & 90 & 90 \\
\hline 12 & 90 & 100 & 100 & 90 & 80 & 90 \\
\hline 13 & 90 & 80 & 90 & 90 & 80 & 90 \\
\hline 14 & 90 & 80 & 90 & 90 & 80 & 90 \\
\hline 15 & 90 & 90 & 100 & 80 & 90 & 80 \\
\hline 16 & 100 & 90 & 90 & 90 & 90 & 90 \\
\hline 17 & 80 & 90 & 90 & 90 & 80 & 90 \\
\hline 18 & 90 & 100 & 100 & 90 & 90 & 60 \\
\hline 19 & 100 & 90 & 100 & 70 & 60 & 70 \\
\hline 20 & 80 & 80 & 80 & 60 & 80 & 80 \\
\hline 21 & 90 & 90 & 80 & 60 & 60 & 80 \\
\hline 22 & 90 & 90 & 100 & 70 & 80 & 60 \\
\hline 23 & 90 & 90 & 100 & 70 & 70 & 60 \\
\hline 24 & 80 & 90 & 90 & 60 & 60 & 70 \\
\hline 25 & 100 & 90 & 80 & 60 & 70 & 60 \\
\hline 26 & 90 & 100 & 90 & 70 & 60 & 80 \\
\hline 27 & 100 & 100 & 100 & 80 & 70 & 60 \\
\hline 28 & 90 & 100 & 100 & 60 & 70 & 70 \\
\hline 29 & 90 & 100 & 90 & 60 & 80 & 60 \\
\hline 30 & 90 & 100 & 90 & 60 & 70 & 70 \\
\hline
\end{tabular}

\begin{tabular}{|c|c|c|c|c|}
\hline & \multicolumn{2}{|c|}{ Control group } & \multicolumn{2}{|c|}{ Experimental group } \\
\hline & $\begin{array}{l}\text { Breaking } \\
\text { load (kg) }\end{array}$ & $\begin{array}{l}\text { Strength } \\
\left(\mathrm{kg} / \mathrm{mm}^{2}\right)\end{array}$ & $\begin{array}{l}\text { Breaking } \\
\text { load (kg) }\end{array}$ & $\begin{array}{l}\text { Strength } \\
\left(\mathrm{kg} / \mathrm{mm}^{2}\right)\end{array}$ \\
\hline 1 & 12.07 & 1.34 & 10.25 & 1.13 \\
\hline 2 & 11.02 & 1.22 & 11.54 & 1.28 \\
\hline 3 & 14.02 & 1.55 & 12.08 & 1.34 \\
\hline 4 & 13.33 & 1.48 & 12.01 & 1.33 \\
\hline 5 & 12.87 & 1.43 & 9.28 & 1.03 \\
\hline 6 & 11.24 & 1.24 & 9.05 & 1.00 \\
\hline 7 & 12.38 & 1.37 & 12.08 & 1.34 \\
\hline 8 & 15.09 & 1.67 & 14.01 & 1.55 \\
\hline 9 & 15.2 & 1.68 & 10.28 & 1.14 \\
\hline 10 & 14.28 & 1.58 & 11.02 & 1.22 \\
\hline 11 & 15.09 & 1.67 & 12.01 & 1.33 \\
\hline 12 & 15.03 & 1.67 & 10.89 & 1.21 \\
\hline 13 & 14.08 & 1.56 & 11.89 & 1.32 \\
\hline 14 & 11.03 & 1.22 & 12.03 & 1.33 \\
\hline 15 & 15.04 & 1.67 & 11.04 & 1.22 \\
\hline 16 & 11.28 & 1.28 & 12.05 & 1.33 \\
\hline 17 & 16.02 & 1.78 & 12.11 & 1.34 \\
\hline 18 & 11.29 & 1.25 & 9.84 & 1.09 \\
\hline 19 & 15.23 & 1.69 & 9.88 & 1.09 \\
\hline 20 & 11.2 & 1.24 & 10.02 & 1.11 \\
\hline 21 & 15.1 & 1.67 & 11.5 & 1.27 \\
\hline 22 & 16.03 & 1.78 & 11.54 & 1.28 \\
\hline 23 & 16.01 & 1.78 & 10.8 & 1.2 \\
\hline 24 & 15.03 & 1.67 & 10.25 & 1.13 \\
\hline 25 & 14.8 & 1.64 & 11.28 & 1.25 \\
\hline 26 & 13.09 & 1.45 & 11.54 & 1.28 \\
\hline 27 & 12.9 & 1.43 & 10.38 & 1.15 \\
\hline 28 & 13.93 & 1.54 & 10.8 & 1.2 \\
\hline 29 & 14.88 & 1.65 & 11.24 & 1.24 \\
\hline 30 & 15.08 & 1.67 & 12.09 & 1.34 \\
\hline
\end{tabular}

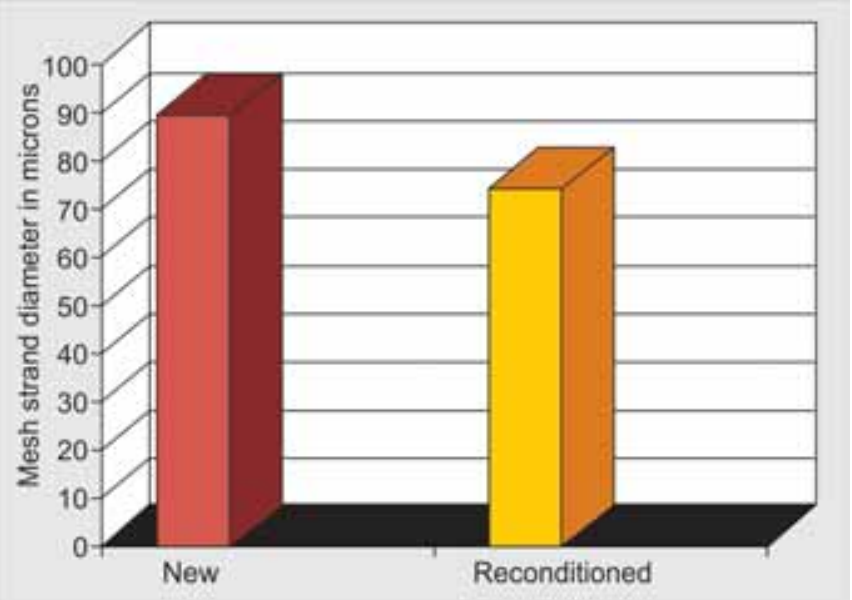

Graph 2: Bar diagram comparing mesh strand diameter of new and reconditioned brackets (tensile group)

\begin{tabular}{|c|c|c|c|c|}
\hline & \multicolumn{2}{|c|}{ Shear group } & \multicolumn{2}{|c|}{ Tensile group } \\
\hline & New & Recycled & New & Recycled \\
\hline Mean & 91.99 & 74.11 & 90.33 & 74.65 \\
\hline Standard deviation & 4.99 & 10.89 & 4.90 & 8.18 \\
\hline z-value & 8.33 & & 8.99 & \\
\hline$p$-value & $<0.0001^{*}$ & & $<0.0001$ & \\
\hline
\end{tabular}

\begin{tabular}{|c|c|c|c|c|}
\hline & \multicolumn{2}{|c|}{ Control group } & \multicolumn{2}{|c|}{ Experimental group } \\
\hline & $\begin{array}{l}\text { Breaking } \\
\text { load (kg) }\end{array}$ & $\begin{array}{l}\text { Strength } \\
\left(\mathrm{kg} / \mathrm{mm}^{2}\right)\end{array}$ & $\begin{array}{l}\text { Breaking } \\
\text { load (kg) }\end{array}$ & $\begin{array}{l}\text { Strength } \\
\left(\mathrm{kg} / \mathrm{mm}^{2}\right)\end{array}$ \\
\hline 1 & 11.56 & 1.28 & 11.04 & 1.22 \\
\hline 2 & 12.02 & 1.33 & 12.02 & 1.33 \\
\hline 3 & 13.08 & 1.45 & 11.03 & 1.22 \\
\hline 4 & 13.02 & 1.42 & 12.04 & 1.33 \\
\hline 5 & 11.92 & 1.32 & 9.8 & 1.08 \\
\hline 6 & 11.08 & 1.23 & 9.08 & 1.00 \\
\hline 7 & 12.01 & 1.33 & 9.10 & 1.01 \\
\hline 8 & 12.82 & 1.42 & 9.23 & 1.02 \\
\hline 9 & 13.01 & 1.44 & 10.23 & 1.13 \\
\hline 10 & 12.02 & 1.33 & 10.43 & 1.15 \\
\hline 11 & 13.04 & 1.44 & 12.01 & 1.33 \\
\hline 12 & 13.28 & 1.47 & 11.2 & 1.24 \\
\hline 13 & 13.92 & 1.54 & 10.08 & 1.12 \\
\hline 14 & 12.92 & 1.43 & 11.05 & 1.22 \\
\hline 15 & 11.28 & 1.25 & 11.03 & 1.22 \\
\hline 16 & 11.58 & 1.28 & 10.28 & 1.14 \\
\hline 17 & 12.02 & 1.33 & 10.05 & 1.11 \\
\hline 18 & 13.01 & 1.44 & 10.05 & 1.16 \\
\hline 19 & 12.22 & 1.35 & 10.25 & 1.13 \\
\hline 20 & 12.92 & 1.43 & 11.43 & 1.27 \\
\hline 21 & 11.98 & 1.33 & 12.23 & 1.35 \\
\hline 22 & 9.92 & 1.1 & 11.58 & 1.28 \\
\hline 23 & 10.03 & 1.11 & 10.9 & 1.21 \\
\hline 24 & 10.38 & 1.15 & 11.35 & 1.26 \\
\hline
\end{tabular}

*p-values — very highly significant 


\begin{tabular}{cccccc|} 
Contd. & \multicolumn{3}{c|}{} \\
\hline & \multicolumn{2}{c}{ Control group } & & \multicolumn{2}{c|}{ Experimental group } \\
\cline { 2 - 3 } \cline { 5 - 6 } & $\begin{array}{c}\text { Breaking } \\
\text { load }(\mathrm{kg})\end{array}$ & $\begin{array}{c}\text { Strength } \\
\left(\mathrm{kg} / \mathrm{mm}^{2}\right)\end{array}$ & & $\begin{array}{c}\text { Breaking } \\
\text { load }(\mathrm{kg})\end{array}$ & $\begin{array}{c}\text { Strength } \\
\left(\mathrm{kg} / \mathrm{mm}^{2}\right)\end{array}$ \\
\hline 25 & 12.34 & 1.37 & & 12.05 & 1.33 \\
26 & 12.82 & 1.42 & & 10.6 & 1.17 \\
27 & 13.02 & 1.44 & & 11.54 & 1.28 \\
28 & 12.99 & 1.44 & & 12.85 & 1.42 \\
29 & 12.02 & 1.33 & & 9.9 & 1.1 \\
30 & 11.92 & 1.32 & 9.34 & 1.03 \\
& & & &
\end{tabular}

calculated. The values were subjected to statistical analysis to find whether the differences in bond strength were statistically significant (Table 6) (Graphs 3 and 4).

\begin{tabular}{|c|c|c|c|c|}
\hline & \multicolumn{2}{|c|}{ Shear bond strength } & \multicolumn{2}{|c|}{ Tensile bond strength } \\
\hline & Control & Experimental & Control & Experimental \\
\hline Mean & 1.53 & 1.24 & 1.35 & 1.20 \\
\hline $\begin{array}{l}\text { Standard } \\
\text { deviation }\end{array}$ & 0.19 & 0.12 & 0.11 & 0.11 \\
\hline z-value & 7.29 & & 5.52 & \\
\hline$p$-value & $<0.0001^{*}$ & & $<0.0001^{*}$ & \\
\hline
\end{tabular}

*p-values—very highly significant

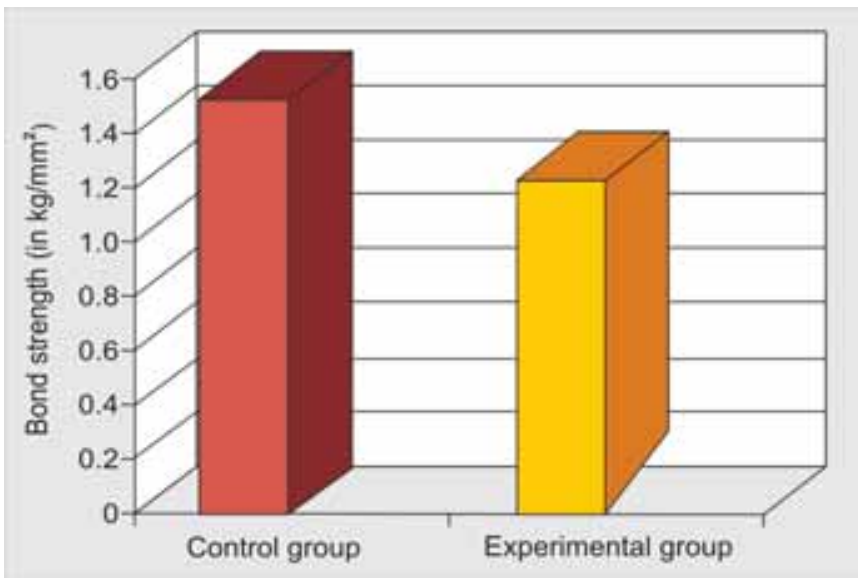

Graph 3: Bar diagram comparing shear bond strength of control and experimental groups

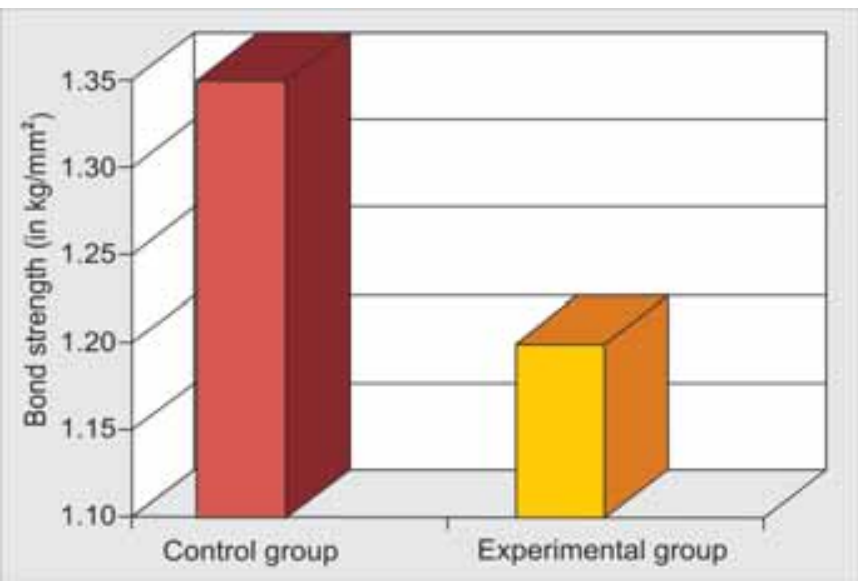

Graph 4: Bar diagram comparing tensile bond strength of control and experimental groups
An analysis of multiple linear regression was done to correlate the mesh strand diameter of new and recycled brackets to their shear bond strength and tensile bond strength separately.

\section{DISCUSSION}

The present study was undertaken to evaluate the effect of a commercial thermal reconditioning procedure on the tensile and shear bond strength of direct bonding TP Begg Brackets (No: 256-650 series) curved base, minimesh type.

The study indicates that the mean tensile bond strength for control and experimental groups were 1.36 and $1.20 \mathrm{~kg} / \mathrm{mm}^{2}$ and the mean shear bond strength were 1.53 and $1.24 \mathrm{~kg} / \mathrm{mm}^{2}$, respectively. It is evident from the above result that there is a significant reduction in bond strength for experimental groups when compared with control groups for both tensile and shear samples.

The bond strength of bracket is affected by the area of bonding base, mesh strand diameter and impurities on surface of the bracket's base. In the present study, the area of bonding base remained the same but showed a decrease in mesh strand diameter.

The possibility of direct loss of material from bracket surface during recycling and electropolishing procedure could reduce the size and effectiveness of the retentive elements of the base, thereby affecting the bond strength of the bracket. This can be attributed as the major cause for the reduction of the bond strength.

The present study showed that reconditioned brackets have weaker bond strength than the new brackets, which cannot be explained on the basis of reduction on mesh diameter alone as shown in charts 1 and 2. Some of the reconditioned brackets showed higher bond strength than the new brackets even though there is a decrease in mesh strand diameter, but majority of the reconditioned brackets showed lower bond strength, which could be attributed to the residues remaining of the strands, especially the central strands because of differential current density during electropolishing. The other factors that may affect the bond strength of the reconditioned brackets are the method of bonding and the recycling process employed. Clinical debonding generally involves uneven shear force applied with pliers or a scalar. Mesh distortion caused by their instruments may greatly affect bond strength of the reconditioned bracket.

The use of heat is a critical factor in recycling, as it influences not only the bond strength but also the microstructure of the brackets. The normal microstructure of the brackets is homogeneous and nongranular. If temperature is maintained above $400^{\circ} \mathrm{C}$ a chromium carbide precipitate is formed and, as a result, a partial disintegration of alloy occurs leading to general weakening of the bracket. 
The reduction ion tensile bond strength of experimental group of this study seems to confirm the findings of various earlier studies. ${ }^{8-11}$ The value of the findings in this study does not correlate with them, which could be attributed to different adhesive of the bracket that has been used in their study. The above-mentioned correlations of this study appear to have a particular relevance in the view of the earlier studies, which have demonstrated that recycled brackets may be inferior in bond strength when compared with new brackets. However, when choosing to reuse a reconditioned bracket for orthodontic treatment, the clinician must accept the fact that there will be a reduction in the bond strength, when compared with new brackets. But, if the loss in strength when compared with the initial strength is still above the clinically required minimum, then reusing of their conditioned brackets can be considered. The decision to reuse a bracket ultimately depends on what magnitude of forces are generated in the mouth throughout the duration of orthodontic treatment. The incisal biting forces are said to be in the range of 14 to $17 \mathrm{~kg}$, ${ }^{12}$ while the maximum occlusal forces are in the range of 31 to $35 \mathrm{~kg} .{ }^{13}$ According to Reynolds (1975), ${ }^{14}$ the average biting force is about $70 \mathrm{~kg} / \mathrm{cm}^{2}$ and the average force transmitted to the bracket during mastication is about 4.5 to $12 \mathrm{~kg}$ per $\mathrm{cm}^{2}$. The maximum orthodontic force (headgear) is quoted to be $1.5 \mathrm{~kg} / \mathrm{mm}^{2}$. This translates into need of not more than 80 $\mathrm{kg} / \mathrm{mm}^{2}$ of bond strength. If we consider the bond strength values of reconditioned brackets above this $80 \mathrm{~kg} / \mathrm{mm}^{2}$, as being necessary to withstand the forces generated in the mouth to be clinically adequate, then the possibility of reusing the brackets, successfully, is more. The orthodontic forces are said to never exceed 450 gm per tooth. ${ }^{1,3,5,6,8,9,15,16}$ Maijersmith (1979) ${ }^{17}$ indicated that bond strength of $10 \mathrm{~kg}$ is adequate for orthodontic appliance. Hence, if we correlate the tensile and shear strength values $\left(1.26\right.$ and $1.50 \mathrm{~kg} / \mathrm{mm}^{2}$, respectively) of the recycled brackets of this study with the above-mentioned contemporary orthodontic force prescription, then, the use of this single resin charring procedure followed by single electron polishing procedure, without compromising on the retention or mechanical precision of Begg mechanism will be adequate enough to resist the forces exerted during the entire orthodontic treatment procedures for a successful orthodontic treatment. However, the validity and the clinical success of multiple reconditioning on the bond strength of the Begg bracket is yet to be investigated.

\section{CONCLUSIONS}

On the basis of this study, it can be concluded that:

1. Mesh strand diameter decreases in mesh-backed brackets as a result of the reconditioning process outlined
2. Tensile and shear bond strength of new direct bonding brackets are greater than the same after reconditioning

3. Reduction in mesh strand diameter, as a result of reconditioning process, does not correlate with the change in bond strength between initial and recycled bondings.

It may also be concluded that the bond strength of reconditioned brackets will be adequate enough to resist the magnitude of forces generated in the mouth, throughout the duration of orthodontic treatment for successful treatment results.

\section{REFERENCES}

1. Buchman DJL. Effects of recycling on metalic direct bond orthodontic brackets. Am J Orthod 1980;77:654-68.

2. Wheeler JJ, Ackerman RJ. Bond strength of thermally recycled metal brackets. Am J Orthod 1983;83:181-86.

3. Wright WL, Powers JM. In vitro tensile bond strength of reconditoned brackets. Am J orthod 1985;87:247-52.

4. Regan D, Noort RV, Keffe CO. The effects of recycling on the tensile bond strength of new and clinically used stainless steel brackets: An in vitro study. Br J Orthod 1990;17:137-45.

5. Mascia E, Chen SR. Shearing strength of recycled direct bonding brackets. Am J orthod 1982:82,211-16.

6. Matasa CG. Pros and cons of the reuse of direct bonded appliances: Clinicians Corner. Am J orthod 1989;96:72-76.

7. Egan FR, Alexanders A, Cartwright GE. Bond strength of rebounded orthodontic brackets. Am J orthod 1996;64-70.

8. Maijer R, Smith DC. Improvements in brackets base design. In Am J Orthod 1983;83:277-81.

9. Evans LB, Powers JM. Factors affecting in vitro bond strength of no-mix orthodontic cements. In Am J Orthod 1985;87: 508-12.

10. Yamada, et al. Tensile and shear bond strength of orthodontic direct bonding adhesives. In J of Dentalmate 1988;4:243-50.

11. Regan D, Masney B, Noort RV. The tensile bond strength of new and rebounded stainless steel orthodontic brackets. In EJO 1993;15:125-35.

12. Garner LD, Kotwal NS. Correlation study of incisive biting force with age and anterior occlusion. J Dent Res 1973;52:698-702.

13. Proffit WR, Fields WH, Nixonwl. Occusal forces in normal and long face adults. Dent Res 1983;62:556-74.

14. Reynolds IR, et al. Direct bonding of orthodontic brackets: A comparative study of adhesives. In BJO 1976;3:143-46.

15. Newman GV. Epoxy adhesives for orthodontic attachements. J Orthod 1965;51:901-12.

16. Wheeler JJ, Ackerman RJ. Bond strength of thermally recycled metal brackets. Am J Orthod 1983;88:181-86.

17. Thompson RE, Way DC. Enamel loss due to prophylaxis and multiple bonding/debonding of orthodontic attachments. Am J Orthod 1981;79:282-95.

\section{ABOUT THE AUTHORS}

\section{Y Narendranath Reddy (Corresponding Author)}

Professor and Head, MNR Dental College Sangareddy, Andhra Pradesh, India, Phone: 919866330093, e-mail: nath_reddy@yahoo.com 


\section{Praveen Kumar Varma}

Reader, Department of Orthodontics, MNR Dental College Sangareddy, Andhra Pradesh, India

\section{Anil G Kumar}

Reader, Department of Orthodontics, MNR Dental College Sangareddy, Andhra Pradesh, India

\section{KV Sujan Kumar}

Senior Lecturer, Department of Orthodontics, MNR Dental College Sangareddy, Andhra Pradesh, India

\section{Surendra V Shetty}

Dean and Head, Department of Orthodontics, Manipal College of Dental Sciences, Mangalore, Karnataka, India 